\title{
A Fundamental Study on Physical Properties of Optimized Sintered Wick Structured Heat Pipe Using Computational Fluid Dynamics Analysis Method
}

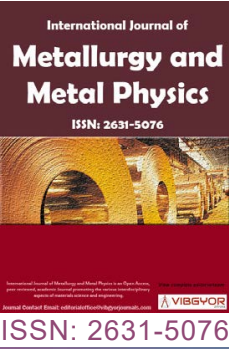

\section{Vikneshwaran* and Shukairol Nizam}

Faculty of Engineering, City University, Selangor, Malaysia

\begin{abstract}
This paper reports the evaluation of physical properties for optimized sintered wick structured heat pipe. The structural design of the heat pipe was executed using CATIA V5 computer aided design software. Upon designing, finite element analysis conducted to evaluate performance of heat pipe were evaluated using ANSYS R19 computer aided manufacturing software. The physical properties of heat pipe evaluated according to physical parameters such as Temperature, Pressure and Velocity. The results obtained achieved the objectives. A low cost solution identified for the problem stated.
\end{abstract}

\section{Keywords}

Heat transfer, Physical properties, Finite element method, Computational fluid dynamics

\section{Introduction}

\section{Introduction to aluminium and heat pipe}

Aluminium Alloy has highly opted for structural applications. 7075 grade has been a mutual choice of raw material selection for heavy-duty manufacturing sectors and construction industries. The advantages are low density, highest tensile strength, ductile and huge fatigue resistant [1].

Heat pipes known as passive equipment. It affords the capacity to transform heat efficiently from one point to another with minimum scale in temperature. A heat pipe is a "double phase" heat transfer mechanism with extremely huge "effective" thermal conductivity. A thin walled pipe with an internal wick structure allows boiling and condensing to occur within the pipe resulting in heat transfer from the hot end to the cooled end [2] Figure 1.0.

\section{Wick structure}

It is a porous structure made of materials like steel, aluminium, nickel or copper in various ranges of porous sizes. The prime purpose of the wick is to generate capillary pressure to transport the working fluid from the condenser to the evaporator. It must also be able to distribute the liquid around the evaporator section at any area where heat is likely to be received by the heat pipe [2] Figure 1.1.

\section{Literature Review}

\section{Simulation and CFD analysis of heat pipe with different wick geometry using CFX}

Miniature cylindrical metal powder sintered wick heat pipe (sintered heat pipe) undoubtedly a unique component with extreme thermal efficiency for high heat flux electronics cooling. This paper reports about Heat pipe designed using Wick ge-

*Corresponding author: Vikneshwaran, Faculty of Engineering, City University, U No, Menara City, 8, Jalan 51a/223, Seksyen 51a, 46100 Petaling Jaya, Selangor, Malaysia|

Accepted: March 10, 2021; Published: March 12, 2021

Copyright: (C) 2021 Vikneshwaran et al. This is an open-access article distributed under the terms of the Creative Commons Attribution License, which permits unrestricted use, distribution, and reproduction in any medium, provided the original author and source are credited.

Vikneshwaran et al. Int J Metall Met Phys 2021, 6:064

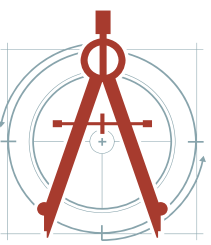




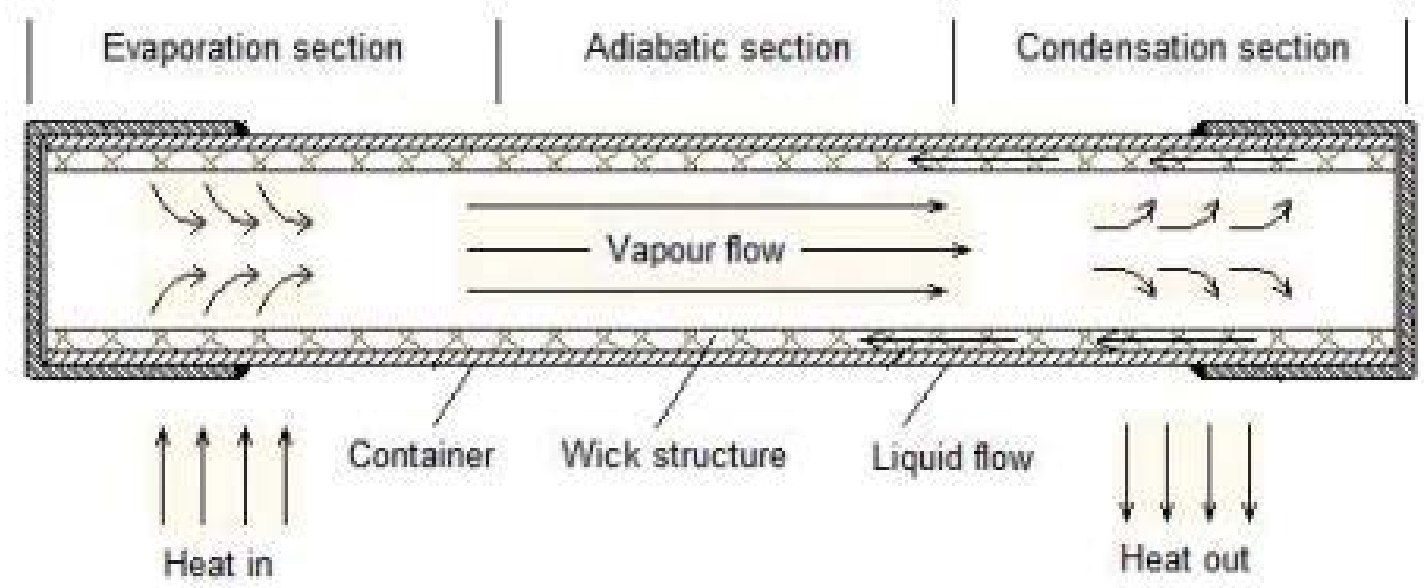

Figure 1.0: Shows the cross-section of heat pipe [2].
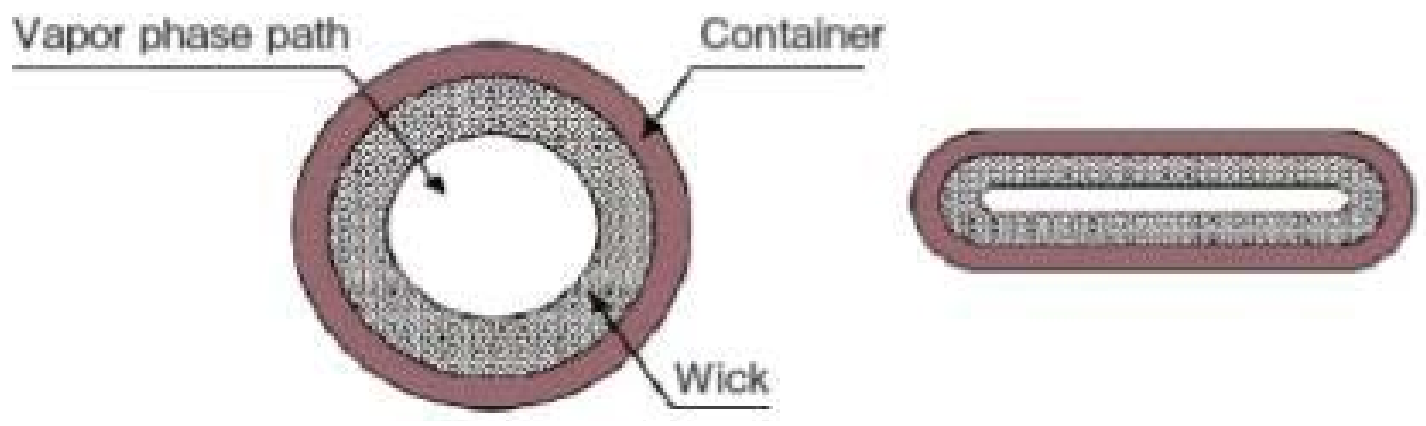

Figure 1.1: Shows the fundamental sintered wick structure design heat pipe [2].

ometry $0.5 \mathrm{~mm}, 0.75 \mathrm{~mm}, 1 \mathrm{~mm}$. The shapes involved are Sintered, V- Groove, and Screen Groove.

For the Heat pipe, the material chosen was silica material. Furthermore, nickel alloy nisil (nickel + silicon) applied as a wick material. Water, Methanol, Aqueous Methanol applied as working fluids. Numerical evaluations accomplished using CFX (the CFD solver program).

Results provided in graphical representation. Main objective of this research is to study the difference between temperature gradient vs. heat transfer coefficient with different wick's, wick shapes and different working fluids [3] Figure 1.2.

\section{CFD analysis of axially wicked heat pipe}

Compared with conventional heat pipes, huge heat transfer rates with improved cooling possibly achieved by Axial Wicked Heat Pipes (AWHP). This exists due to increase in heat transfer area. Experiments conducted to examine the effect of variation in heat input and inclination angle during performance of AWHP. SS304 opted as the material for container and water as the working fluid for AWHP. Interior phase of the outer pipe covered with single layer of screen mesh wick. Surface and vapour temperatures were determined for various heat inputs and inclination angles at steady state conditions and isothermal characteristics of AWHP considering uniform heating application identified. Results proves that increase in heat input, the vapor temperature difference between the evaporator and condenser section decreases for all inclination angles of AWHP. The temperature difference between the evaporator and condenser end in axial direction is the least for vertical position of AWHP at all levels of heat input. This depicts the isothermal characteristic of concentric annular heat pipe. Thermal resistance decreased possibly due to enhancement in nucleate boiling activity and this improved the heat transfer with increase in heat input. Least thermal resistance found at vertical position of AWHP [4].

\section{Problem Statement and Objectives}

\section{Problem statement}

Producing an optimized heat pipe prototype 

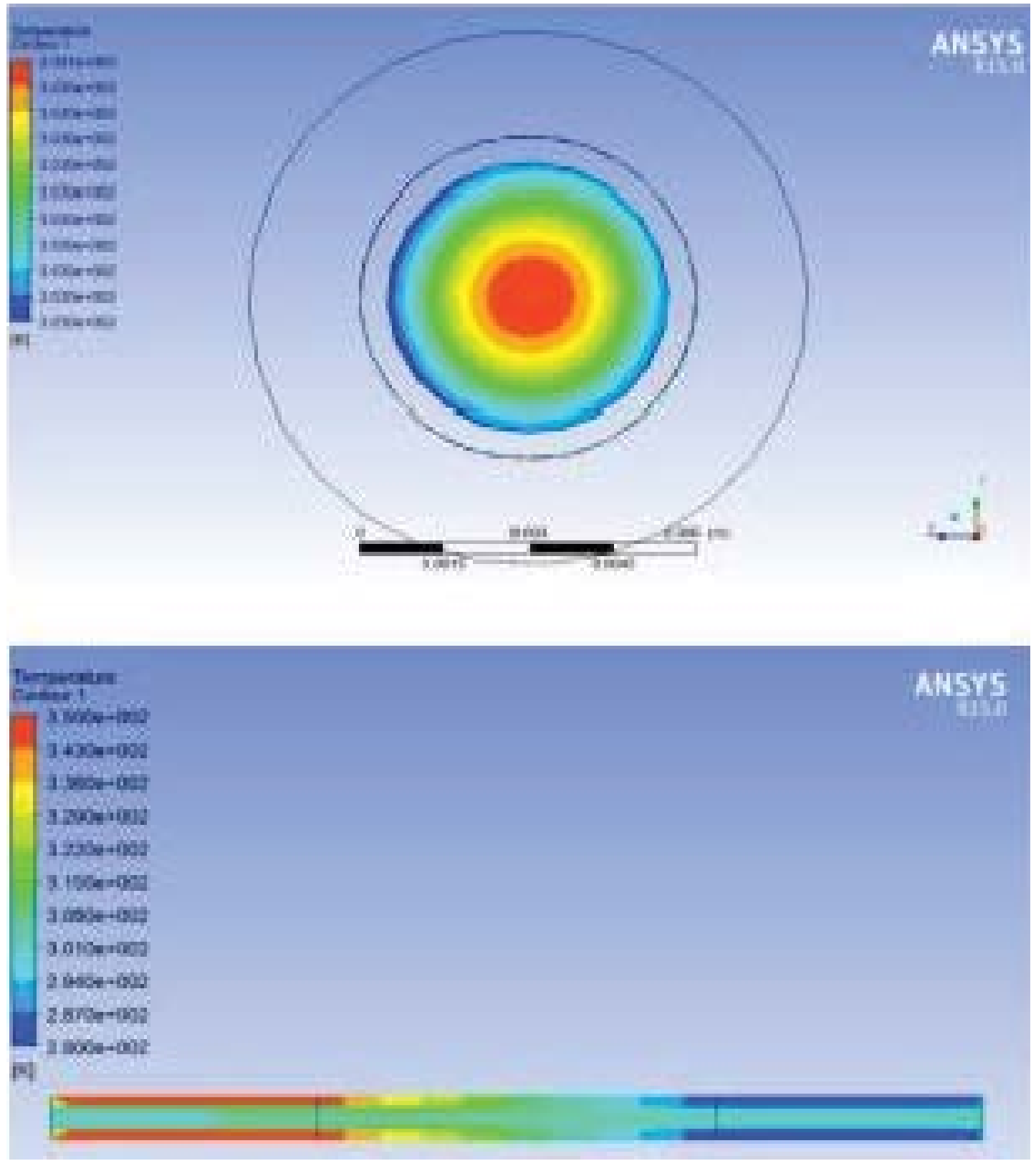

Figure 1.2: Contours of sintered wick heat pipe using CFD method [3].

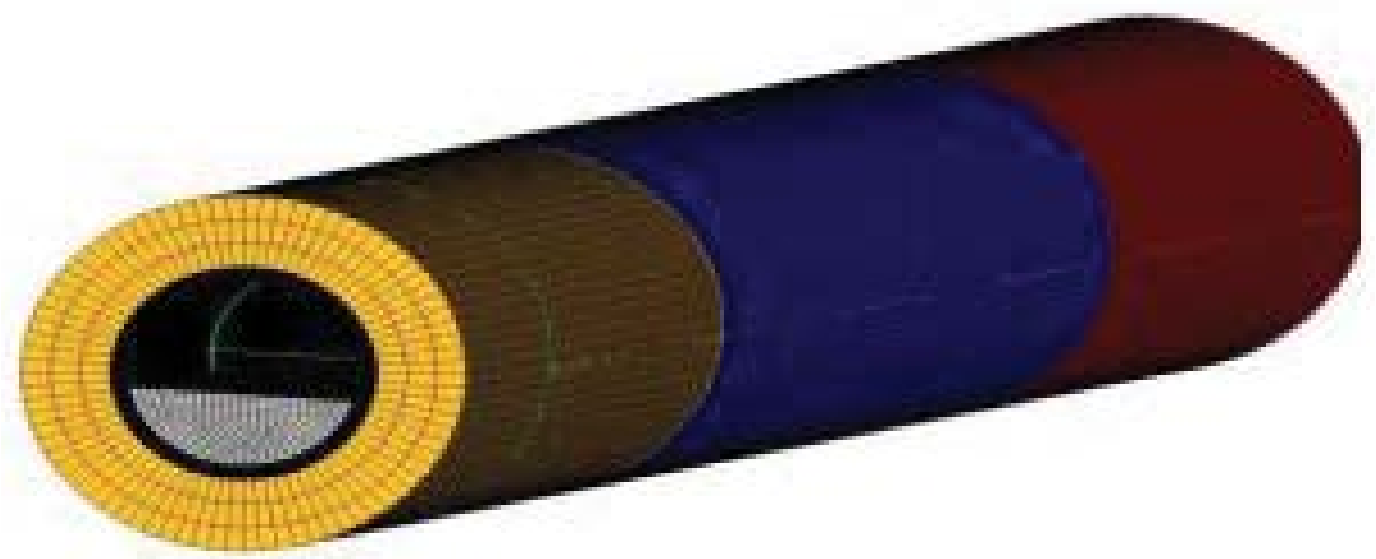

Figure 1.3: Reference of 3-Dimensional basic sintered wicked heat pipe [3]. 
conventionally leads to high cost in terms of fabrication and features installation. Conventional testing method to analyze the physical properties turns challenging to obtain accurate and precise results in short period according to finite element method.

\section{Research objectives}

i. To design an optimized sintered wicked 3Dimensional heat pipe using CAD Software.

ii. To analyze the physical properties of the designed heat pipe using finite element method with simulation software to prevent from spending huge cost.

iii. To conduct simulation study the impacts of physical properties such as Temperature, Pressure and Velocity of the optimized heat pipe.

\section{Methodology}

\section{Design of sintered wicked heat pipe}

To achieve the first objective, an optimized sintered wicked heat pipe designed using CatiaV5 software. Figure 1.3 was referred to design. The designed heat pipe consist numerous chamfers and curves due to ensure a smooth flow of fluid and pressure Table 1.0, Figure 1.4 and Figure 1.5.

\section{Chronology of finite element analysis}

To achieve the second objective, finite element analysis conducted using ANSYS R19 software. Flu-

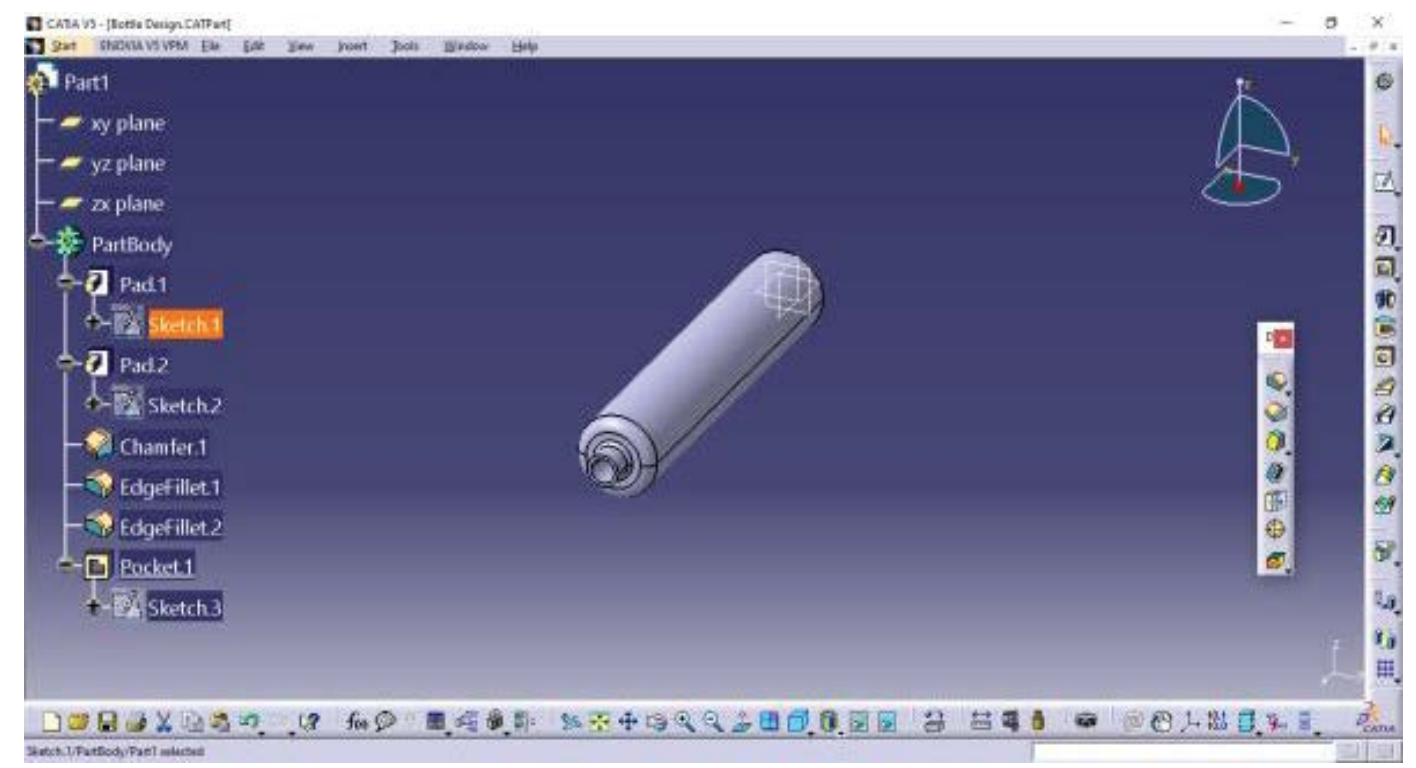

Figure 1.4: Isometric view of optimized sintered wick heat pipe.

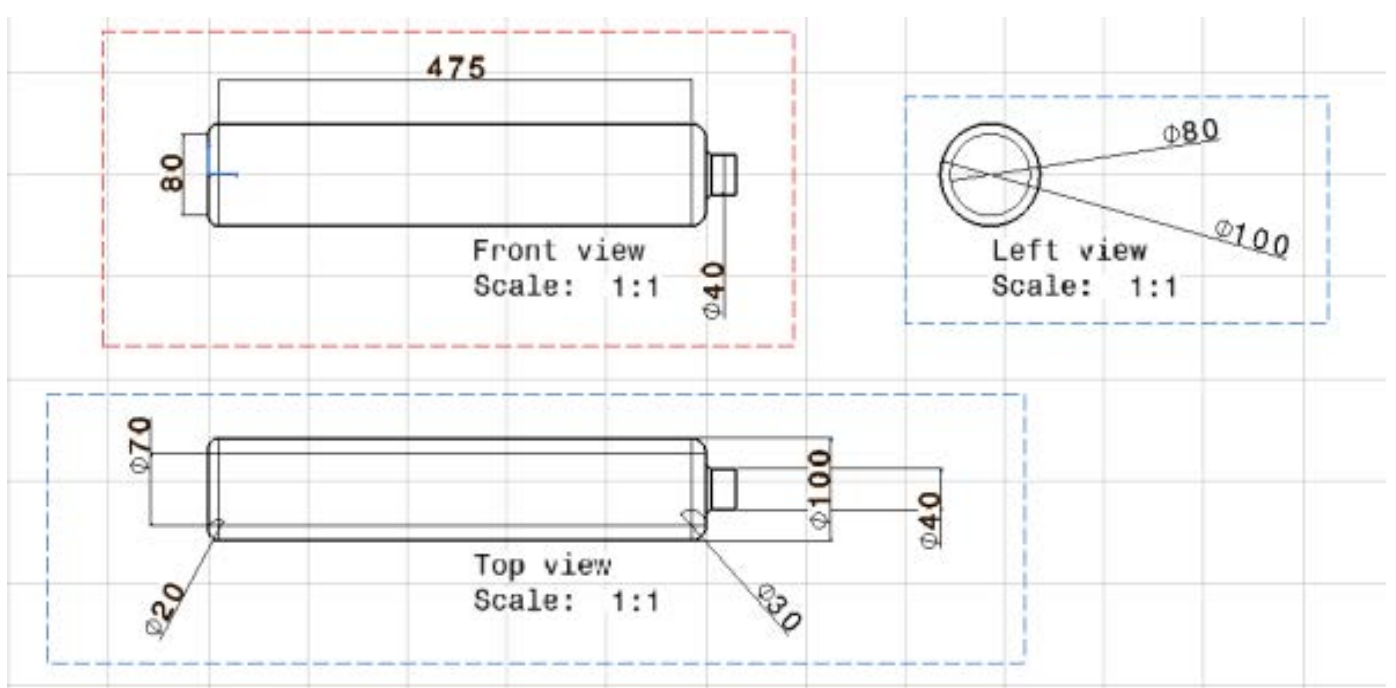

Figure 1.5: 3-Dimensional views of designed heat pipe. 


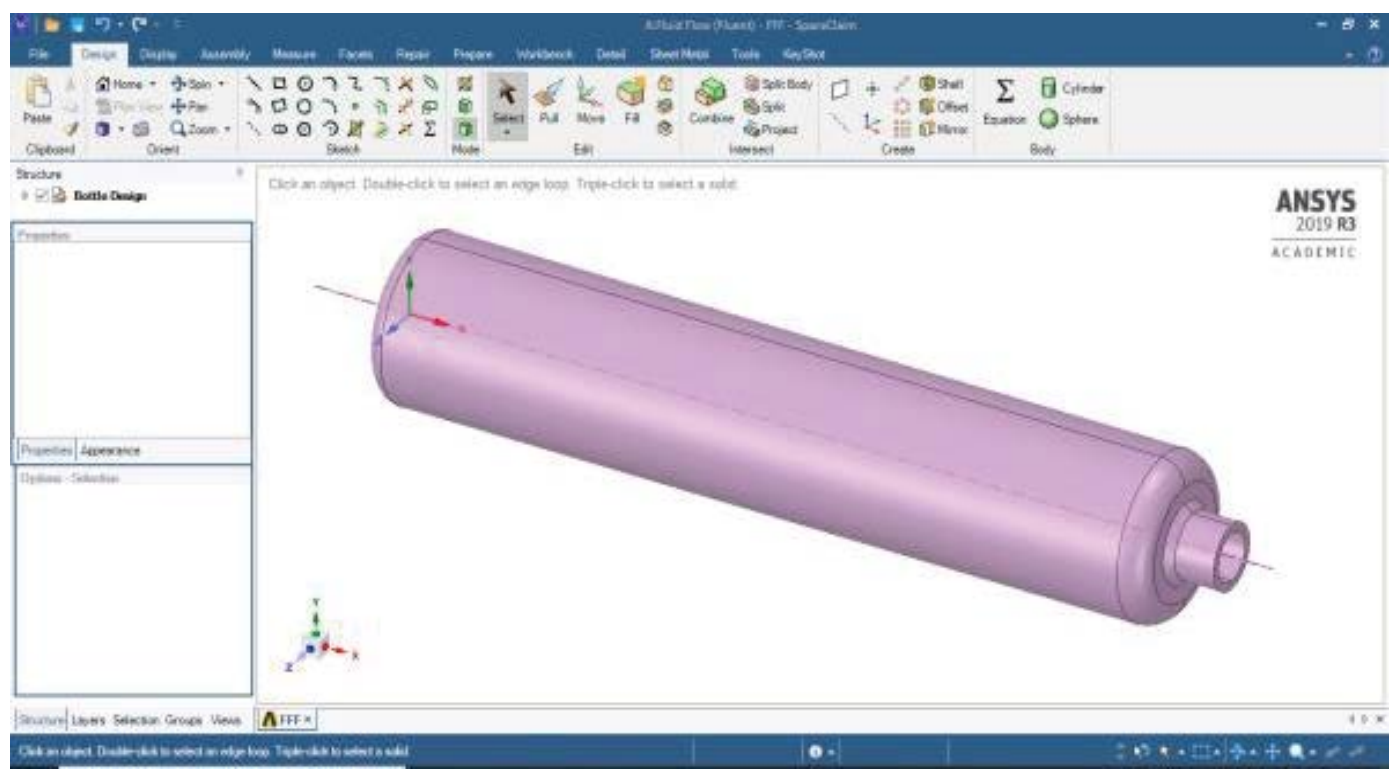

Figure 1.6: Heat pipe design in geometry database.

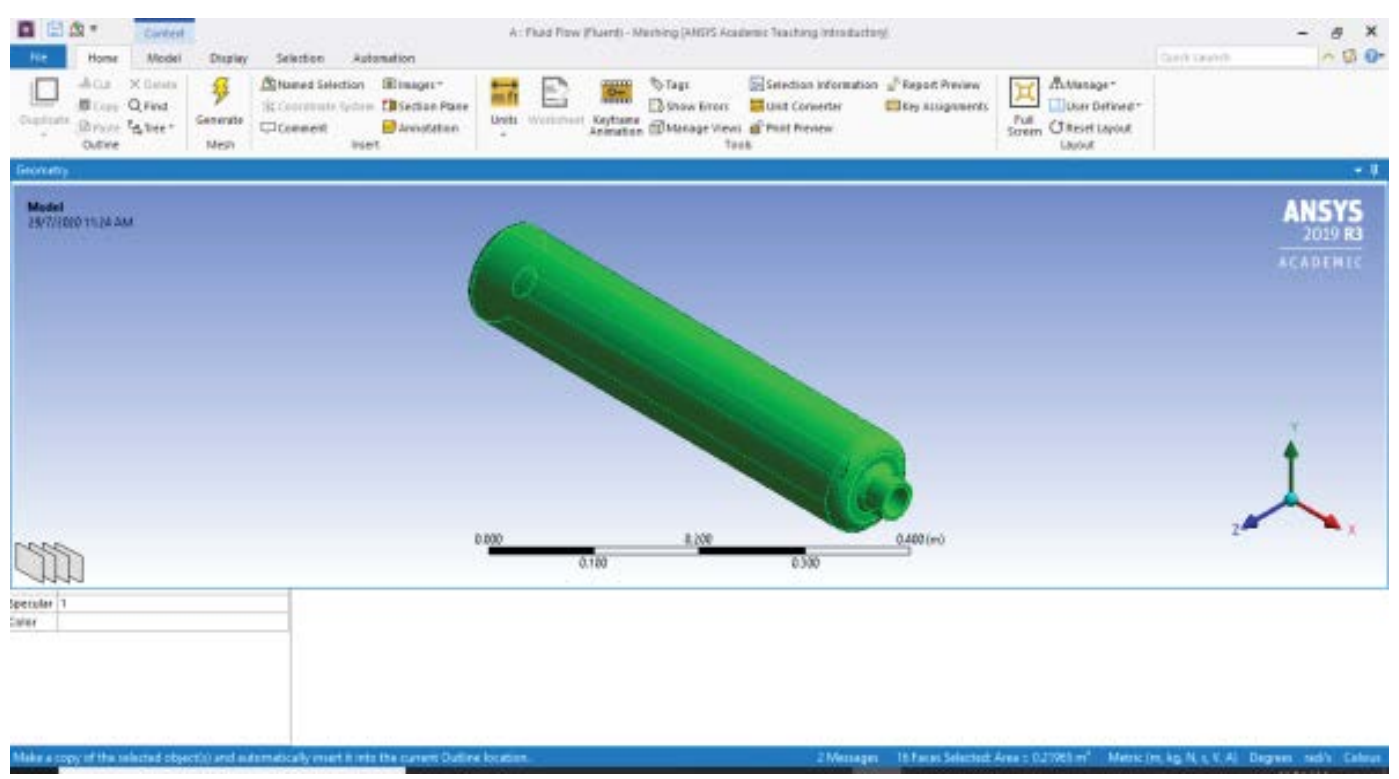

Figure 1.7: Surface capturing and labelling at mesh database.

Table 1.0: Tabulation of dimensions for designed sintered heat pipe.

\begin{tabular}{|l|l|}
\hline Parameters & Dimensions \\
\hline Total length & $530 \mathrm{~mm}$ \\
\hline Total thickness & $100 \mathrm{~mm}$ \\
\hline Inlet diameter & $40 \mathrm{~mm}$ \\
\hline External diameter & $60 \mathrm{~mm}$ \\
\hline Wick thickness & $5 \mathrm{~mm}$ \\
\hline
\end{tabular}

ent analysis method chosen to proceed the analysis.

Initially, the design were loaded in the geometry
Table 1.1: Tabulation of specifications for heat pipe.

\begin{tabular}{|l|l|}
\hline Material name & Aluminium \\
\hline Applied density & $2719 \mathrm{~kg} / \mathrm{m}^{3}$ \\
\hline Applied specific heat & $1871 \mathrm{~J} / \mathrm{kg}-\mathrm{k}$ \\
\hline Applied thermal conductivity & $100^{\circ} \mathrm{C} / 373 \mathrm{~K}$ \\
\hline
\end{tabular}

database. Upon loading, the data updated Figure 1.6.

Meshing process generated to capture entire elements involved in evaluation. In prior of meshing, the elements were labelled as Inlet and Surface Figure 1.7. 


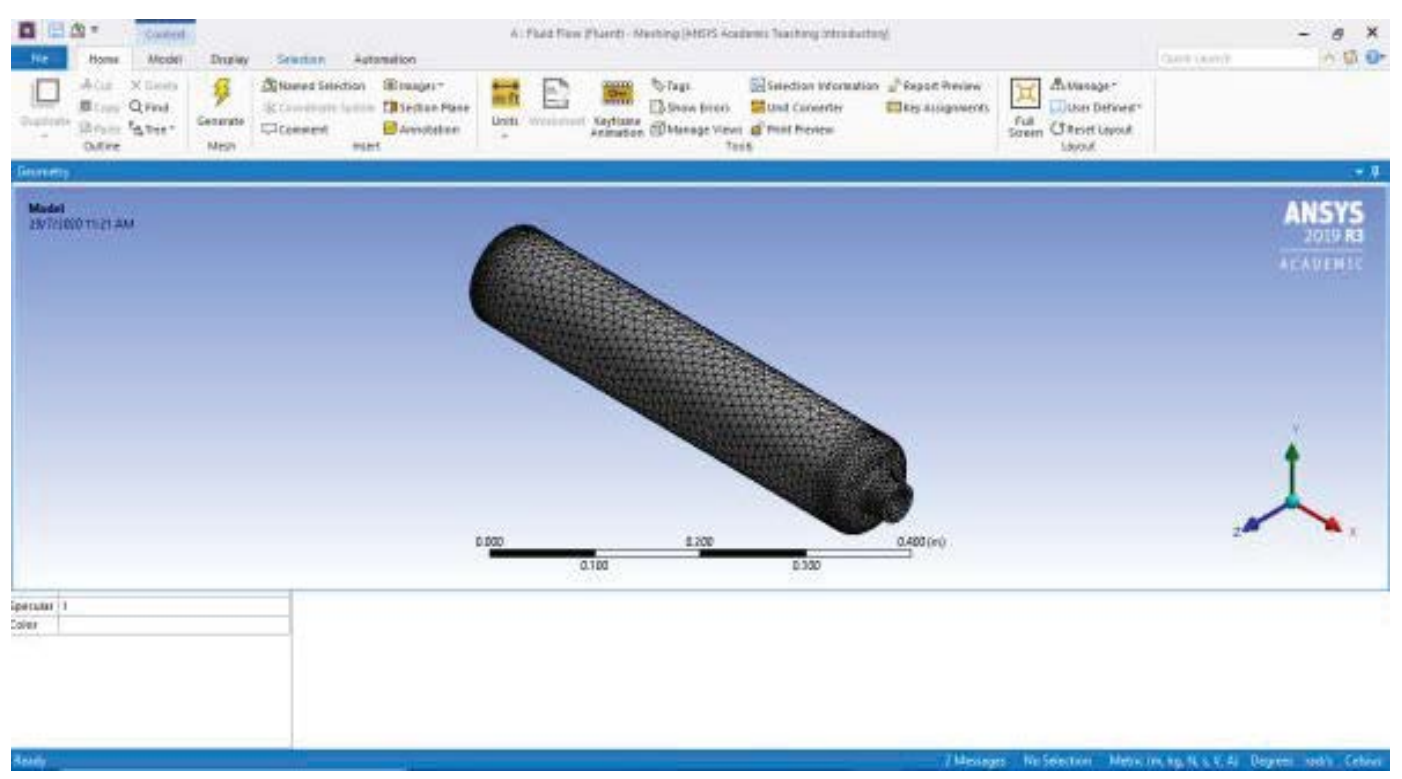

Figure 1.8: Meshing process successful.

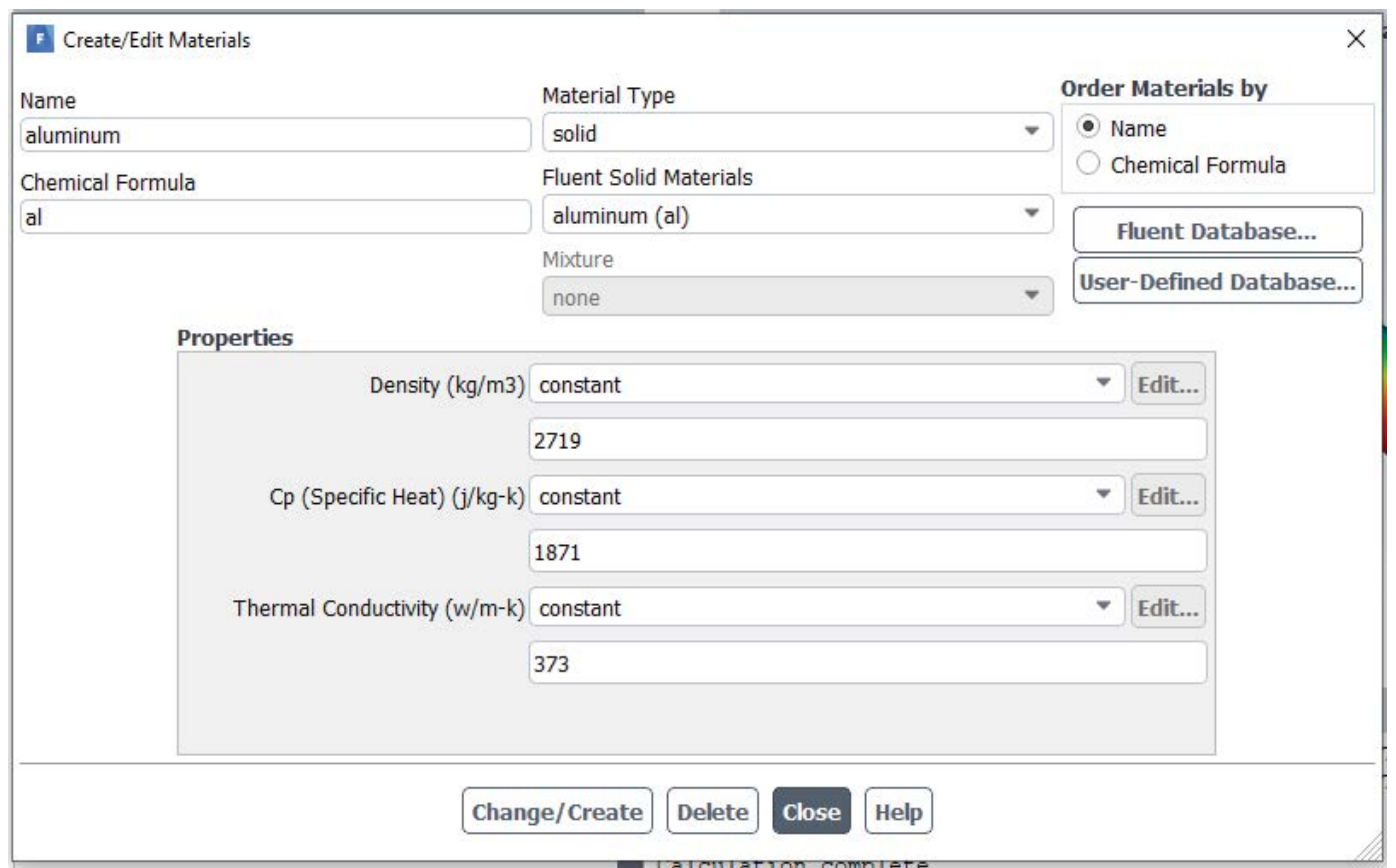

Figure 1.9: Database of Create/Edit materials with specifications for heat pipe surface.

Table 1.2: Tabulation of applied specifications for fluid properties.

\begin{tabular}{|l|l|}
\hline Material type & Fluid \\
\hline Applied density & $1500 \mathrm{~kg} / \mathrm{m}^{3}$ \\
\hline Applied specific heat & $1006.43 \mathrm{~J} / \mathrm{kg}-\mathrm{k}$ \\
\hline Applied thermal conductivity & $2.0242 \mathrm{w} / \mathrm{m}-\mathrm{k}$ \\
\hline Applied viscosity & Constant \\
\hline
\end{tabular}

Table 1.3: Tabulation of specifications for external wall surface of heat pipe.

\begin{tabular}{|l|l|}
\hline Surface & Wall \\
\hline Applied temperature & $100{ }^{\circ} \mathrm{C} / 373 \mathrm{~K}$ \\
\hline Wall thickness & $0.01 \mathrm{~m}$ \\
\hline
\end{tabular}

Table 1.4: Tabulation of maximum temperature at Inlet.

\begin{tabular}{|l|l|}
\hline Surface & Velocity Inlet \\
\hline Max temperature & $300^{\circ} \mathrm{C} / 573 \mathrm{~K}$ \\
\hline
\end{tabular}


Meshing process successfully accomplished whereby entire finite elements are captured and eligible for evaluation Figure 1.8.

At setup database, Energy icon activated. At create and edit materials icon selected the desired materials for the applied geometry design. Aluminum (al) was selected. Converted the material type to solid and followed by filling the properties column according to given data Table 1.1, Table 1.2, Table 1.3, Table 1.4, Table 1.5, Figure 1.9, Figure 2.0, Figure 2.1, Figure 2.2 and Figure 2.3.

\section{Analysis method}

Upon completion of data applications, proceeded to solution process to evaluate. Determined the level of iterations at 480 to evaluate the computational fluid dynamics solutions. As per increase in iterations well noticed the changes occurs in simulation of graph during the calculations in progress. As the calculations accomplished, clicked the contours icon to view the 3-Dimensional results upon simulation. Selected the named surfaces and click Save/Display to obtain the output Figure 2.4.

\section{Results and Discussion}

\section{Velocity impact in heat pipe}

According to my third research objective, the analysis conducted to test the thermal characteristics of heat pipe Figure 2.5. The velocity rate at $100 \mathrm{~m} / \mathrm{s}$ has resulted as per Figure 2.6 below. From observation, I noticed that concentration of heat is high at the bottom surface known as Evaporation section. The simulation result at vapour phase path is reddish contour at evaporation section and finally changes into blue at the condensing section.

Therefore, it's understood that the velocity applied at the bottom vapour phase path increased the pressure of hot air at the evaporation section and performs the heat distribution slowly from evaporation stage to medium cooled stage at adiabatic section which is green contour and finally to blue contour at condensing section.

Finally, the blue contour states that the hot fluid has become cold as per the role of heat pipe Figure 2.5 and Figure 2.6.

\section{Pressure impact in heat pipe}

As per observation from Figure 2.7, the overall pressure contour concludes that, the heat is uniformly distributed. Because the contour at evaporation section is green and slowly turns, light blue at adiabatic section and finally becomes dark blue contour at the condensing section.

As the surface area of container is larger compared to vapour phase path, the air particles col-

Table 1.5: Tabulation of applied velocity at Inlet.

\begin{tabular}{|l|l|}
\hline Surface & Inlet \\
\hline Velocity magnitude & $100 \mathrm{~m} / \mathrm{s}$ \\
\hline
\end{tabular}

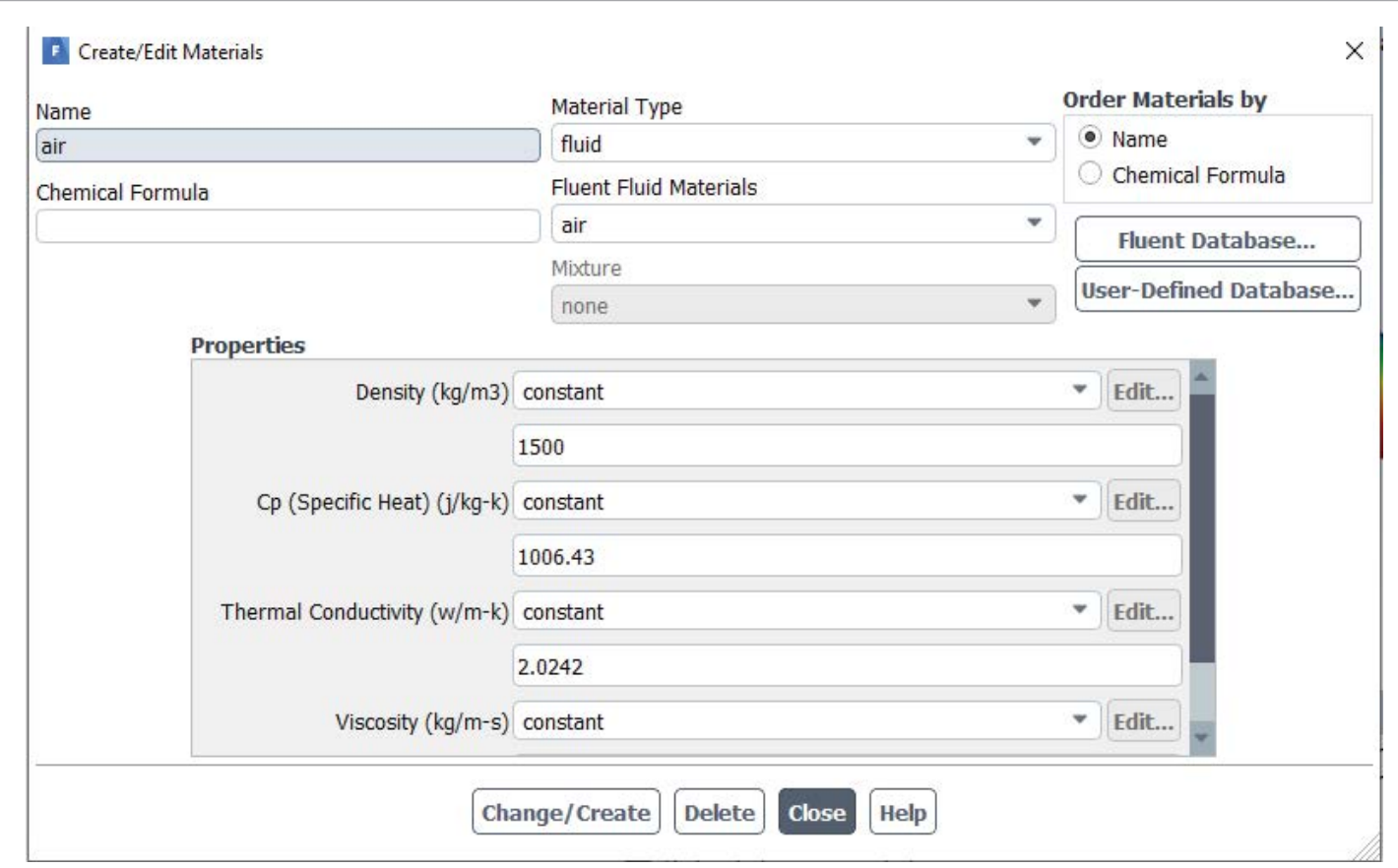

Figure 2.0: Database of Create/Edit materials with specifications for fluid. 


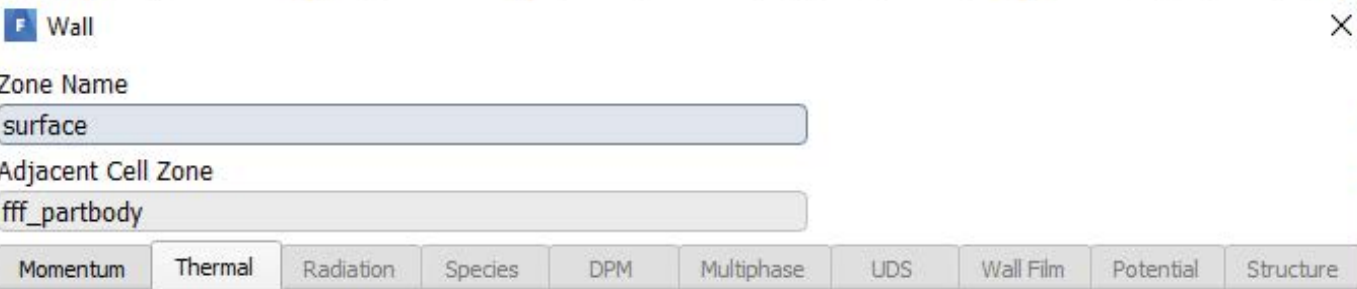

\begin{tabular}{|c|c|c|c|c|c|c|c|c|c|}
\hline Momentum & Thermal & Radiation & Species & DPM & Multiphase & UDS & Wall Film & Potential & Structure \\
\hline
\end{tabular}

Thermal Conditions

Heat Flux
Temperature
Convection
Radiation
Mixed
via System Coupling
via Mapped Interface

Material Name
aluminum

OK Cancel Help

Figure 2.1: Database of Create/Edit materials with specifications for external wall.

\begin{tabular}{|c|c|c|c|c|c|c|c|c|}
\hline \multicolumn{7}{|c|}{$\begin{array}{l}\text { F Velocity Inlet } \\
\text { Zone Name }\end{array}$} & \multirow{2}{*}{\multicolumn{2}{|c|}{$\times$}} \\
\hline \multicolumn{7}{|c|}{ inlet } & & \\
\hline Momentum & Thermal & Radiation & & cies & DPM & Multiphase & Potential & UDS \\
\hline \multicolumn{7}{|c|}{ Temperature (k) 573} & \multicolumn{2}{|c|}{$\nabla$} \\
\hline & & & K & Cancel & Help & & & \\
\hline
\end{tabular}

Figure 2.2: Database of velocity Inlet.

lides smoothly. This shows the atmosphere is warm at the interior surface of container even though the vapour path is still hot.

As the pressure level is not harmful, it prevents the structure from cracking or fractured Figure 2.7.

\section{Temperature distribution in heat pipe}

According to temperature distribution analysis in Figure 2.8, the heat pipe has successfully transferred the hot vapour to condensed fluid. The statement a thin walled pipe with an internal wick structure allows boiling and condensing to occur within the pipe resulting in heat transfer from the hot end to the cooled end proved again in this simulation $[2,5]$.

The distribution of heat is smooth as witnessed 


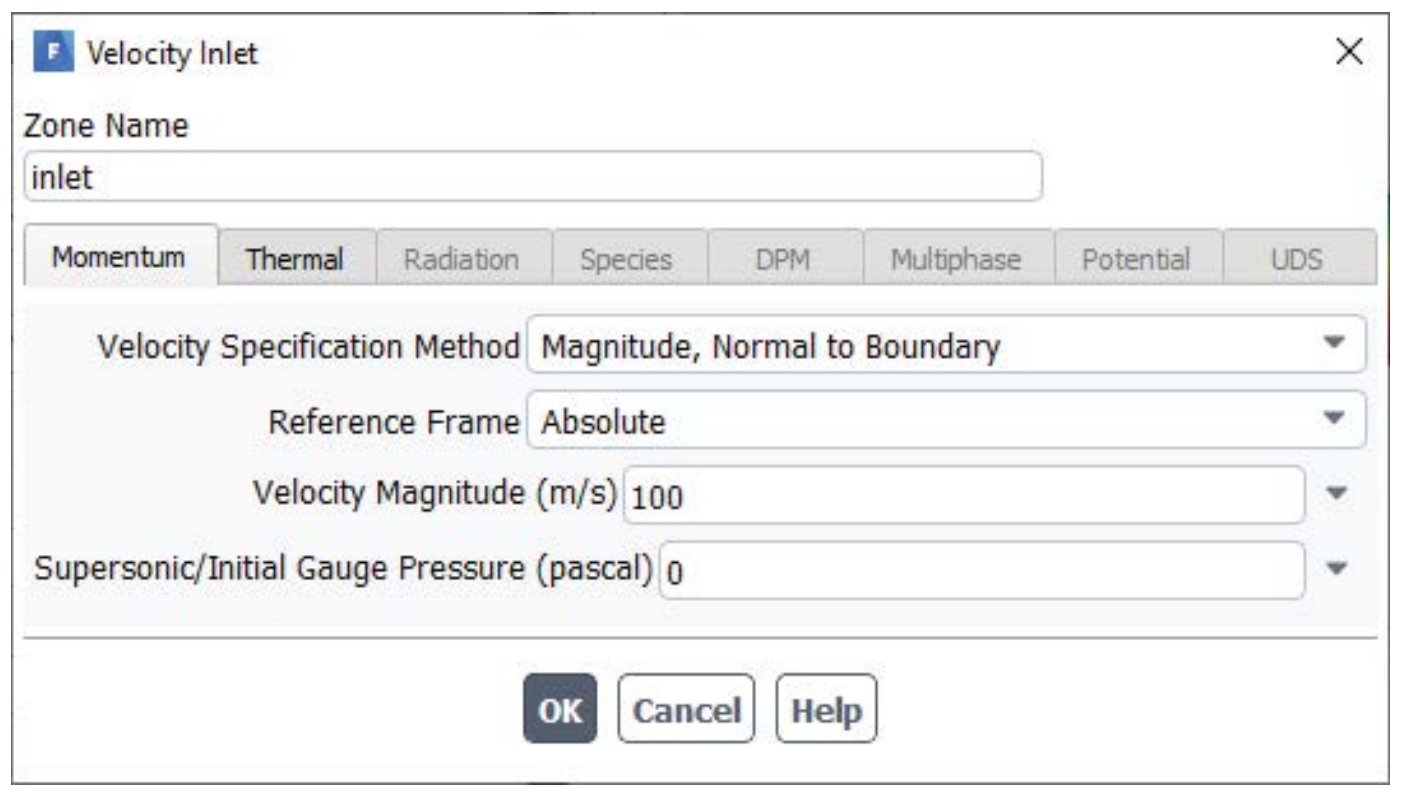

Figure 2.3: Database of Inlet.

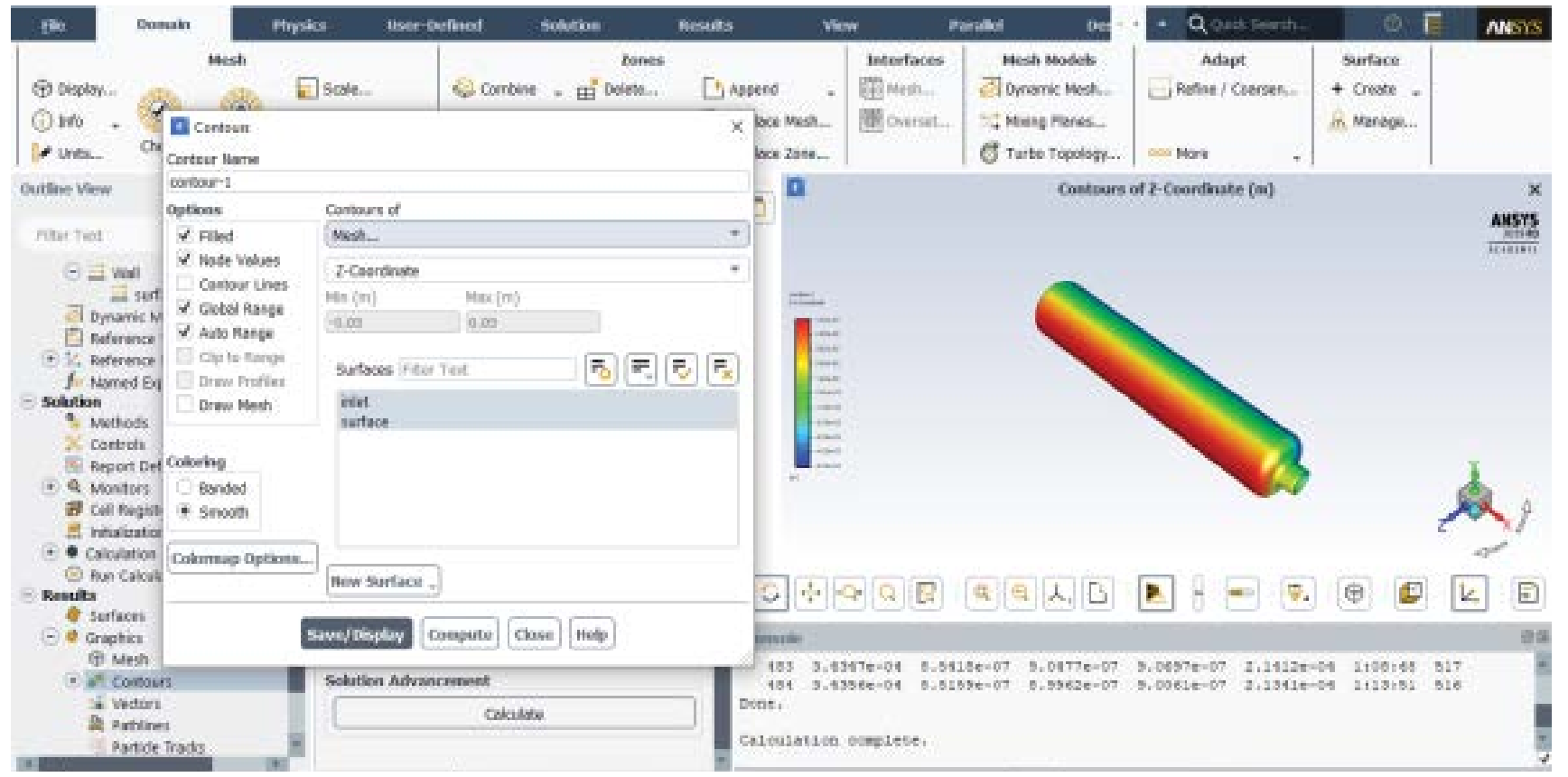

Figure 2.4: Result of mesh contour upon analysis.

clearly. It shows the vapour phase path carries good thermal conductivity, which results in good thermal efficiency.

The adiabatic process turns successful, by compressing the heat at adiabatic section and convert it to condensed air turned fluid. Aluminium material been a right choice for the pipe construction due to prove its tendency to withstand the applied temperatures from $100{ }^{\circ} \mathrm{C} / 373 \mathrm{~K}$ until $300^{\circ} \mathrm{C} / 573 \mathrm{~K}$.

\section{Conclusion}

Predominantly, I would confidently mention that the research objectives achieved without any technical flaw. Computational Fluid Dynamics (CFD) method to conduct Finite Element Analysis turned successful. Results obtained for optimized heat pipe are according to standard specifications and parameters. Through the results, I witnessed that the tendency of physical properties such as 


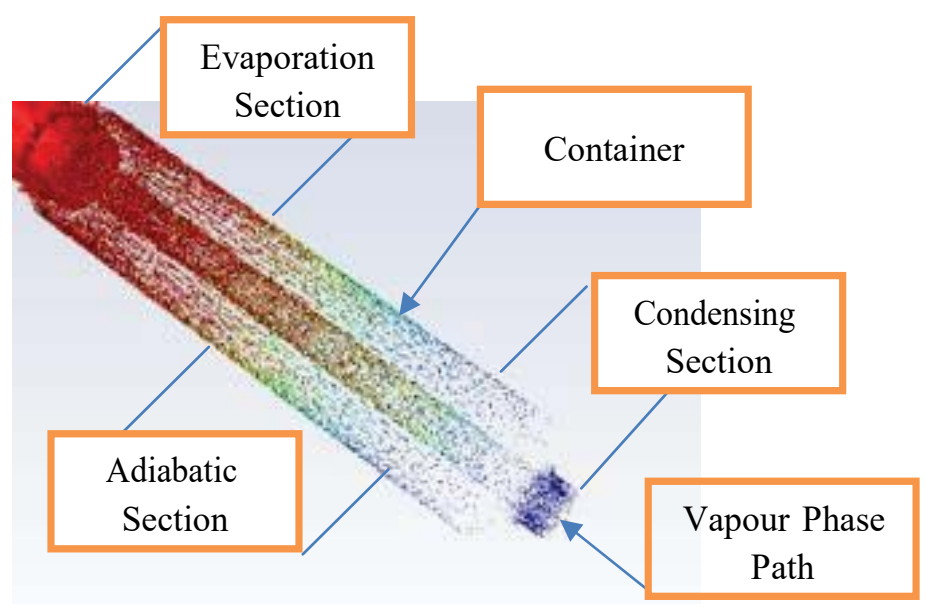

Figure 2.5: Shows the cross-section of resultant heat pipe [2].

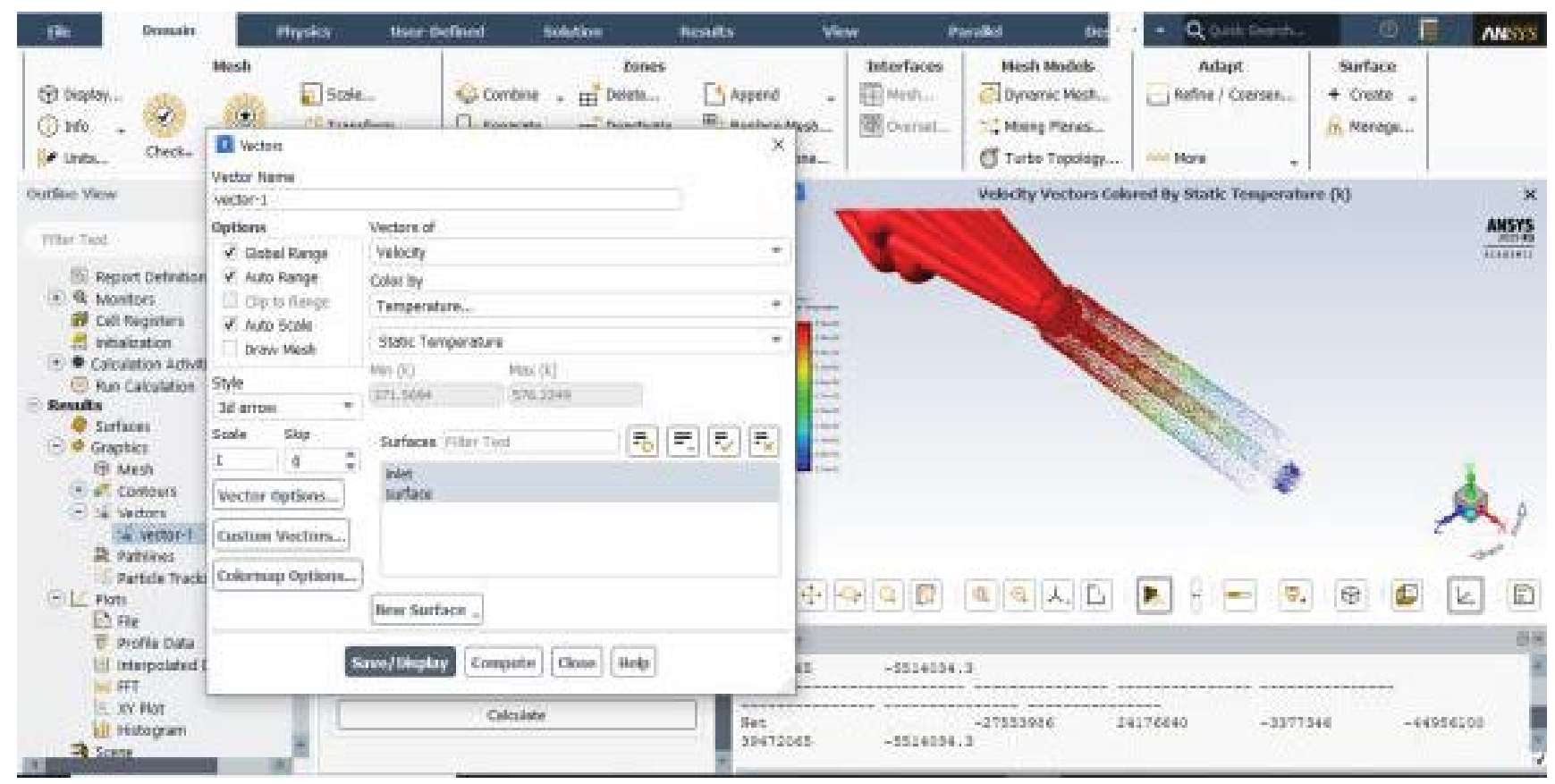

Figure 2.6: Contour result of applied velocity rate. 


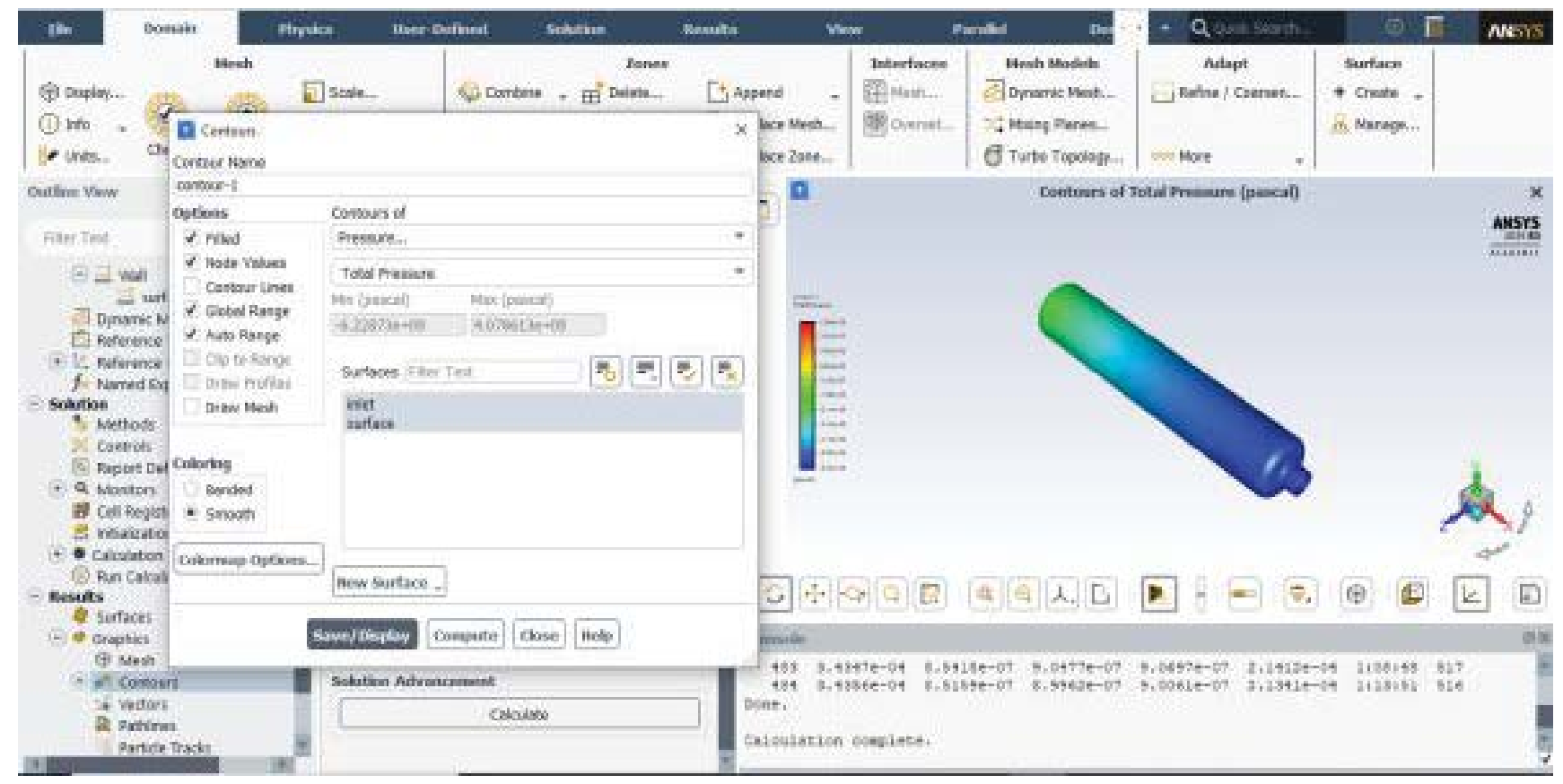

Figure 2.7: Contour result of pressure flow in heat pipe.

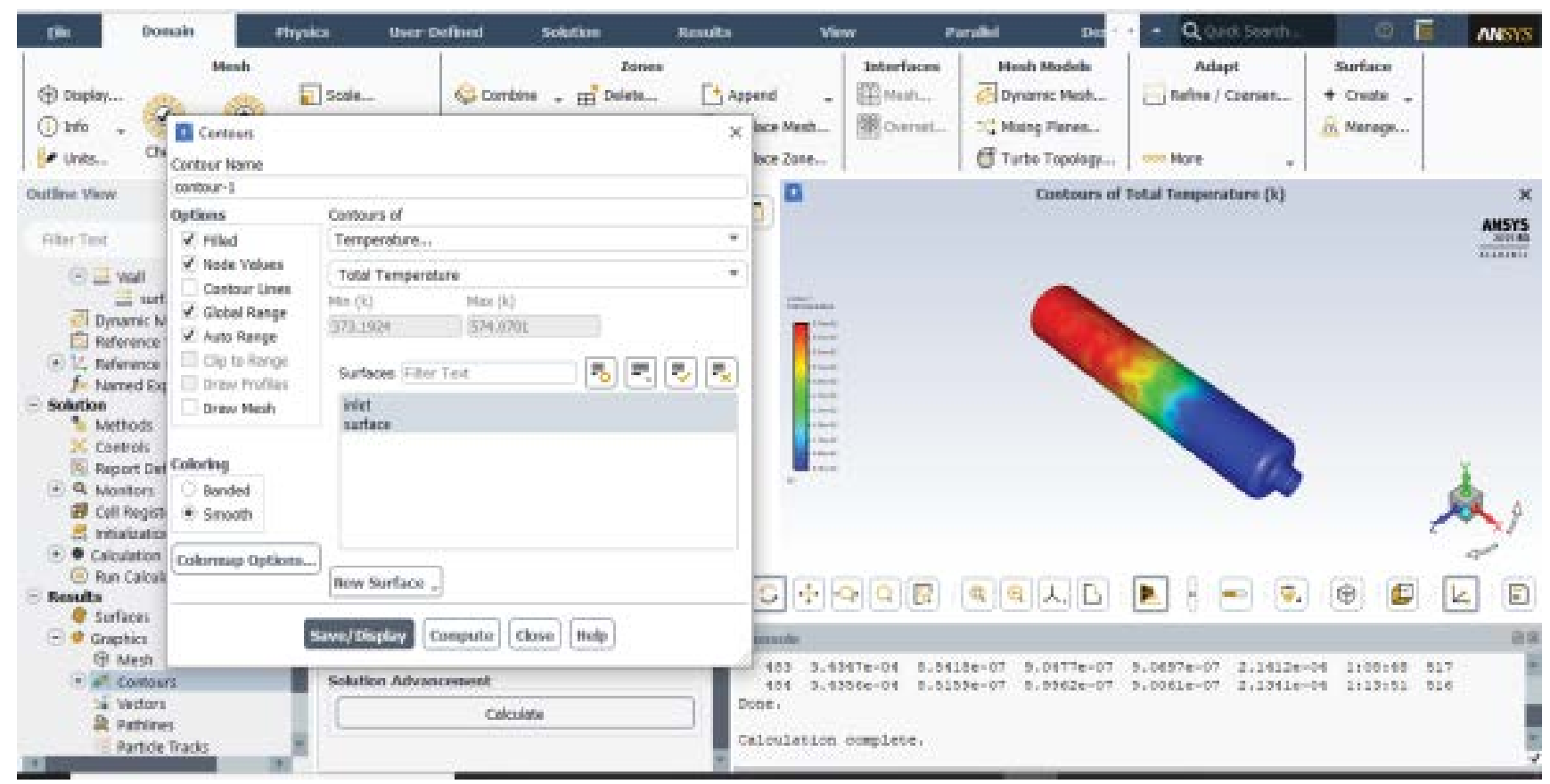

Figure 2.8: Contour result of temperature distribution in heat pipe.

Temperature, Pressure and Velocity precisely evaluated in numerical values using CFD method. The references in literature reviews helped more in conducting the methodology. The output of simulations proved that CFD simulations are unique and reliable to explain the performance of prototypes applies thermodynamics theories and applications.

To conclude my research, I endorse that heat pipe is unique invention to learn thermal characteristics of a heat transfer mechanisms. The effect of core elements during heat transfer such as conduction, convection and condensation are well investigative, through simulations of heat pipe under different conditions. These measures provides more advantages to improve the sustainability of a heat pipes in future with more added features. 


\section{References}

1. Pickens JR, Laboratories MM (1990) High-strength aluminum $\mathrm{P} / \mathrm{M}$ alloys. ( $2^{\text {nd }}$ edn), Properties and selection: Nonferrous alloys and special-purpose materials, ASM Handbook, 200-215.

2. Nemec $P$ (2018) Porous structures in heat pipes. Porosity- Process, Technologies and Applications.

3. Naveenkumar C, Kumar PV, Kumar KD (2015) Simulation and CFD analysis of heat pipe with different wick geometry using CFX. International Journal of Thermal Technologies 5: 210-213.

4. Ramya N, Kanth AR (2017) CFD analysis of axially wicked heat pipe. International Journal of Innovative Technology and Research 5: 6416-6424.

5. Paneliya S, Prajapati P, Patel U, Trivedi I, Patel A, et al. (2019) Experimental and CFD analysis on heat transfer and fluid flow characteristic of a tube equipped with variable pitch twisted tape. E3S Web of Conferences, 116. 